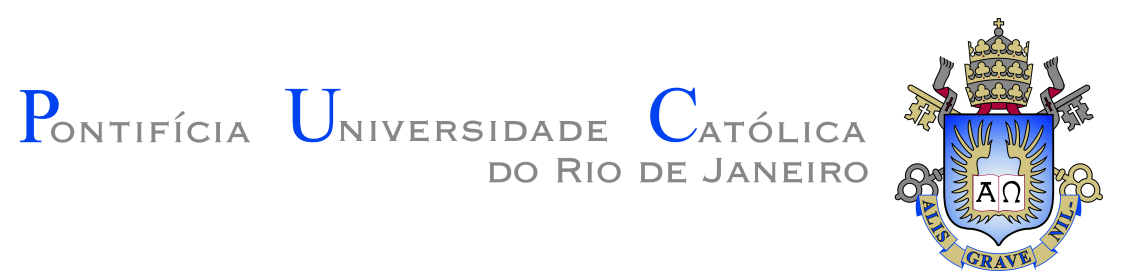

Fabio Wanderley Guerra

Engenharia de Estórias

Um estudo sobre a geração e narração automática de

estórias

Dissertação de Mestrado

Dissertação apresentada como requisito parcial para obtenção do grau de Mestre pelo Programa de Pós-graduação em Informática do Departamento de Informática da PUCRio

Orientador: Prof. Antonio Luz Furtado 


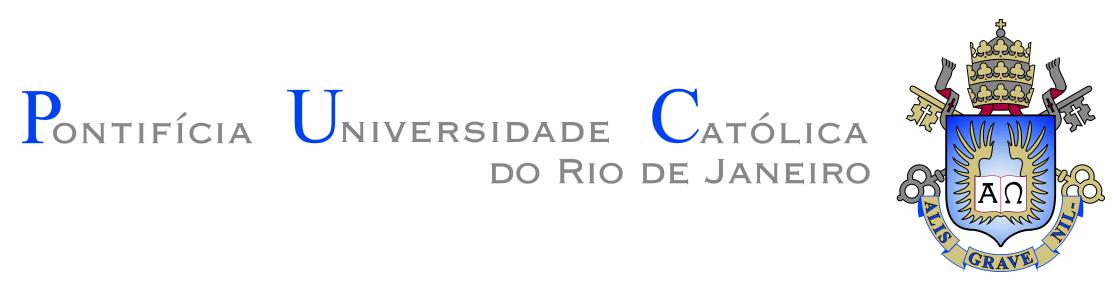

Fabio Wanderley Guerra

\title{
Engenharia de Estórias
}

Um estudo sobre a geração e narração automática de estórias

Dissertação apresentada como requisito parcial para obtenção do grau de Mestre pelo Programa de Pós-graduação em Informática do Departamento de Informática do Centro Técnico Científico da PUC-Rio. Aprovada pela Comissão Examinadora abaixo assinada.

\author{
Prof. Antonio Luz Furtado \\ Orientador \\ Departamento de Informática - PUC-Rio
}

Prof. Bruno Feijó

PUC-Rio

Prof. Marco Antonio Casanova

PUC-Rio

Prof. José Eugenio Leal

Coordenador Setorial do Centro Técnico Científico -

PUC-Rio

Rio de Janeiro, 28 de março de 2008 
Todos os direitos reservados. É proibida a reprodução total ou parcial do trabalho sem autorização da universidade, do autor e do orientador.

Fabio Wanderley Guerra

Formou-se como técnico em eletrônica pela Escola Técnica em Eletrônica "Francisco Moreira da Costa" em 2000 e graduouse em Engenharia da Computação pela Pontifícia Universidade Católica do Rio de Janeiro no ano de 2005. Durante a graduação atuou principalmente em projetos de pesquisa e desenvolvimento na área de computação gráfica e jogos digitais.

Ficha Catalográfica

Guerra, Fabio Wanderley

Engenharia de estórias: um estudo sobre a geração e narração de estórias / Fabio Wanderley Guerra; orientador: Antonio Luz Furtado. - 2008.

106 f: il. ; $30 \mathrm{~cm}$

Dissertação (Mestrado em Informática) - Pontifícia Universidade Católica do Rio de Janeiro, Rio de Janeiro, 2008.

Inclui bibliografia

1. Informática - Teses. 2. Engenharia de estórias. 3. Geração automática de estórias. 4. Narração digital de estórias. 5. Geração de linguagem natural. 6. Inteligência artificial. I. Furtado, Antonio Luz. II. Pontifícia Universidade Católica do Rio de Janeiro. Departamento de Informática. III. Título. 
Dedico este trabalho a Ana Carolina, minha mulher, esposa, amiga e companheira. 


\section{Agradecimentos}

A Deus por escrever a mais bela de todas as estórias.

À minha família por ter sempre me incentivado a estudar e aprender mais, sabendo compreender o tempo que precisei estar longe.

Aos meus amigos, de quem acabei me distanciando durante o período de estudos.

À minha mulher, por estar sempre do meu lado me apoiando nos momentos bons e ruins. Por ter me dado força nos momentos em que pensei em desistir.

Ao meu orientador, por me dar a liberdade de me aprofundar neste assunto.

Ao Börje, por ter sido a única pessoa com quem eu podia conversar a respeito do assunto dessa dissertação.

Ao CNPq e à PUC-Rio, pelos auxílios concedidos, sem os quais este trabalho não poderia ter sido realizado e por estarem contribuindo ao desenvolvimento científico no Brasil. 


\section{Resumo}

Guerra, Fabio Wanderley; Furtado, Antonio Luz. Engenharia de Estórias. Rio de Janeiro, 2008. 106p. Dissertação de Mestrado Departamento de Informática, Pontifícia Universidade Católica do Rio de Janeiro.

Nesta dissertação é estudado o problema de geração e narração de estórias, cuja relevância tem sido cada vez mais reconhecida, principalmente em decorrência da popularização de meios de comunicação interativos, tais como a TV digital e os jogos digitais. O trabalho partiu de uma revisão do estado da arte, destacando os principais modelos para representação de estórias e as técnicas mais utilizadas na criação de obras literárias. Foi proposto o uso do termo 'engenharia de estórias' para enfatizar que a tarefa de geração e narração de estórias deve ser encarada como um processo de engenharia. O problema fundamental foi dividido em três subproblemas. O primeiro diz respeito a como gerar as estórias, o segundo a como contá-las ao público e o último é sobre como construir, armazenar e consultar a base de conhecimento usada na engenharia de estórias. Por fim, como estudo de caso, foi projetado e programado um protótipo capaz de gerar e narrar estórias automaticamente. A geração é efetuada por um planejador, usando o algoritmo de Redes de Tarefas Hierárquicas. Para a narração, é utilizado um gerador de textos em linguagem natural. A base de conhecimento é armazenada na forma de documentos XML tendo sido implementada uma ferramenta para facilitar sua preparação.

\section{Palavras-chave}

Engenharia de Estórias. Geração Automática de Estórias. Narração Digital de Estórias. Geração de Linguagem Natural. Inteligência Artificial. 


\section{Abstract}

Guerra, Fabio Wanderley; Furtado, Antonio Luz. Story Engineering. Rio de Janeiro, 2008. 106p. MsC Thesis — Departamento de Informática, Pontifícia Universidade Católica do Rio de Janeiro.

This dissertation investigates the problem of story telling and generation, whose increasingly recognized relevance is mostly due to the popularization of interactive media, such as digital TV and video-games. The work initiates with a state of the art survey, detailing the major story representation models and the most used methods in literary work production. The use of the term 'story engineering' was proposed to emphasize that story telling and generation should be viewed as an engineering process. The fundamental problem was divided into three subproblems. The first one is how to generate stories, the second is how to tell them to the public and the last is how to create, store and query the knowledge base used for story engineering. Finally, as a case study, a prototype capable of automatically generating and telling stories was designed and programmed. Generation is done by a planner, using the Hierarchical Task Network algorithm. Storytelling applies a natural language generation tool. The knowledge base is stored under the form of XML documents, and a tool was implemented to simplify their preparation.

\section{Keywords}

Story Engeneering. Automatic Story Generation. Interactive Storytelling. Natural Language Generation. Artificial Intelligence. 


\section{Sumário}

1 Introdução $\quad 11$

1.1 Por Que Gerar Estórias? 11

1.2 Motivação 12

$\begin{array}{lll}1.3 & \text { Objetivo } & 12\end{array}$

$\begin{array}{lll}1.4 & \text { Organização do Documento } & 13\end{array}$

2 Trabalhos Relacionados $\quad \mathbf{1 4}$

2.1 Sistemas de Geração de Estórias 14

$\begin{array}{lll}2.1 .1 & \text { Tale-spin } & 15\end{array}$

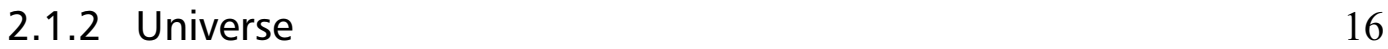

$\begin{array}{ll}2.1 .3 \text { Minstrel } & 17\end{array}$

2.1.4 Mimesis 18

$\begin{array}{lll}2.1 .5 & \text { Façade } & 18\end{array}$

$\begin{array}{ll}2.1 .6 \text { Logtell } & 19\end{array}$

2.2 Modelos de Estórias 20

2.2.1 Aristóteles 21

2.2.2 Divisão em Níveis 21

2.2.3 Funções Literárias $\quad 22$

2.2.4 Monomito 23

2.3 Métodos para criação de estórias 24

2.3.1 Uma Boa Estória Bem Contada 24

2.3.2 Personagens 25

$\begin{array}{ll}2.3 .3 \text { Fábula } & 26\end{array}$

$\begin{array}{ll}2.3 .4 & \text { Relato } \\ & 29\end{array}$

3 Engenharia de Estórias $\quad 31$

3.1 Interactive Storytelling 31

3.2 Inteligência Narrativa 32

3.3 Engenharia de Estórias 32

3.4 Problema fundamental 33

$\begin{array}{lll}3.5 & \text { Subproblemas } & 34\end{array}$

3.5.1 Gerador de Estórias 36

3.5.1.1 Gerenciador de Enredo 37

3.5.2 Contador de Estórias 37

3.5.2.1 Representação da Estória 37

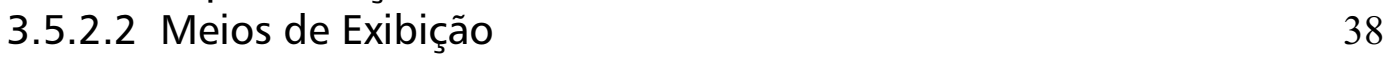

3.5.2.3 Narrativas Interativas $\quad 39$

3.5.2.4 Adaptação 39

3.5.3 Base de conhecimento 40

3.5.3.1 Tipos de informação $\quad 40$

3.5.3.2 Repositório de Estórias 41

3.5.3.3 Reuso 41

3.5.3.4 Conhecimento de Senso Comum 41

3.6 Conclusão 42 
4 Estudo de Caso $\quad 43$

4.1 Descrição Geral da Arquitetura 43

4.2 Geração 45

4.2.1 Estórias Pré-Definidas e Estórias Geradas Dinamicamente 45

4.2.2 Planejamento de Estórias 46

4.2.2.1 Planejamento Automatizado 47

4.2.2.2 Complexidade do planejamento STRIPS 48

4.2.2.3 Classificação dos Sistemas de Planejamento 49

4.2.2.4 Rede de Tarefas Hierárquicas $\quad 50$

4.2.3 Métodos para Criação de Estórias 51

4.2.3.1 Método Proposto 51

4.2.3.2 Personagens $\quad 52$

4.2.3.3 Situações Dramáticas 53

4.2.3.4 Apresentação dos Personagens 54

4.2.3.5 Monomito $\quad 54$

4.2.3.6 Estado Inicial 56

4.3 Narração de Estórias $\quad 56$

4.3.1 Meios de Comunicação para Narração de Estórias 56

4.3.2 Geração de Texto em Linguagem Natural 56

$\begin{array}{lll}4.3 .3 \text { Sintaxe } & 57\end{array}$

4.3.4 Descrição de Uma Fábula 58

4.3.5 Descrição do Léxico 58

4.3.6 Descrição da Conjugação de Verbos

4.3.7 Descrição do Mapeamento de Eventos 60

4.3.8 Implementação $\quad 61$

4.3.9 Uma Arquitetura para a GLN 61

4.3.9.1 Planejamento do Documento 61

4.3.9.2 Microplanemento 63

4.3.9.3 Realização Sintática 64

4.4 Base de Conhecimento 65

$\begin{array}{lll}4.5 & \text { Ferramenta de Autoria } & 67\end{array}$

5 Considerações Finais $\quad \mathbf{7 2}$

$\begin{array}{lll}5.1 \text { Contribuições } & 73\end{array}$

$\begin{array}{lll}5.2 & \text { Trabalhos Futuros } & 73\end{array}$

6 Referências Bibliográficas $\quad 75$

A Descrição da Conjugação dos Verbos $\quad \mathbf{8 0}$

$\begin{array}{lll}\text { B } & \text { Descrição do Léxico } & \mathbf{8 6}\end{array}$

C Descrição do Mapeamento de Eventos $\quad 90$

D Descrição de uma Fábula $\quad 97$ 


\section{Lista de figuras}

2.1 Estória gerada pelo Tale-Spin 16

$\begin{array}{lll}2.2 & \text { Estória gerada pelo Universe } & 17\end{array}$

$\begin{array}{lll}2.3 & \text { Estória gerada pelo Minstrel } & 17\end{array}$

3.1 Esquema para a geração e a narração de estórias 35

3.2 Gerador de Estórias 36

4.1 Arquitetura utilizada para o estudo de caso 44

4.2 Estrutura Sintática $\quad 57$

4.3 Arquitetura para a GLN 62

$\begin{array}{lll}4.4 & \text { Tela inicial da ferramenta de autoria } & 67\end{array}$

4.5 Edição de um método $\quad 68$

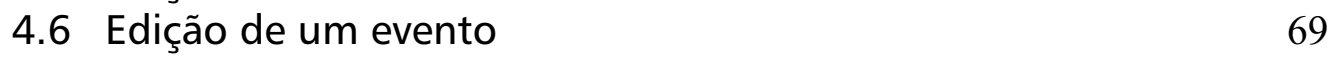

$\begin{array}{ll}\text { 4.7 Exibição da hierarquia de tarefas } & 70\end{array}$

4.8 Exibição da lista de tarefas e estados correspondentes 71 